\title{
Procrastination and its Relationship with Mental Health among Children and Adolescents
}

\author{
*Mohammad Q Abdullah \\ Department of Counseling Psychology, University of Aleppo, Syria
}

Submission: July 15, 2017; Published: July 26, 2017

*Corresponding author: Mohammad Q Abdullah, Department of Counseling Psychology, University of Aleppo, Syria; Email: mk.abdalah@yahoo.com

\begin{abstract}
Procrastination affects many people across life span and influences overall effectiveness of individual and organization especially among children and adolescents inside and outside the schools. The objective of this study is to investigate the relationship between procrastination and mental health with regarding the variables of gender and developmental stage among a sample children and adolescents. The sample of participants was selected from basic teaching schools in Aleppo city for the $4^{\text {th }}, 5^{\text {th }}$ grades of children and $7^{\text {th }}, 8^{\text {th }}, 9^{\text {th }}$ grades of adolescents, and gender (males and females). The sample size was (268) students (133 males, and (135) females, ranging between 10-15 years old. The tools of the study was Procrastination Scale which developed by the researcher and the Mental Health Scale developed by Al-Rahhal 2011. The results of the study revealed that there was significant differences between males and females in procrastination (males were higher than female), and between children and adolescents (among adolescents higher than among children). On the other hand, there was no significant correlation between procrastination and awareness and acceptance of one's self and others, courage, personal and social adjustment, while there was negative significant correlation between procrastination and trusts in one's self and others, freedom of winless, perception of reality and objects, love of the self/ others, and straightness..
\end{abstract}

Keywords: Procrastination, Mental Health, Children and Adolescents

\section{Introduction}

Procrastination is extremely prevalent and pernicious form of self-regulatory failure, or the tendency to postpone an activity under one's control to the last possible minute, or even not to perform it at all, that is not entirely understood. Procrastination is the deferment of actions or tasks to a later time, or even to infinity. It is the avoidance, or deferment, without good reason, of an intended or scheduled until later. The word itself comes from the Latin word procrastinates: pro (forward) and crustiness (of tomorrow). Procrastination is very common and takes place in everyday behaviors. Even though it has been growing for decades and is considered a serious problem today, it wasn't regarded as a serious psychological problem and thus ignored by psychologists for much of history Brown [1].

The term "procrastination" refers to delaying tasks you consider as urgent or necessary and doing something else instead, the substitution work having lower priority and being less essential. And the best definition for procrastination is the delaying of task that was originally planned despite expecting to be worse off for the delay Thakkar [2]. Not all delay, though, is procrastination. Delay is part of structuring and prioritizing, whereas procrastination is needless voluntary postponement of tasks undertaken in the knowledge that it may be harmful to you concerning your performance or feelings. Because the delays is irrational, people end up voluntarily choosing a course of action They know will not maximize their physical, psychological and material well-being. Procrastination is occasionally used in a positive sense. Several writers have mentioned it as a functional delay or as avoiding rush Bernstein [3], Chu and Choi [4], Ferrari [5].

Although virtually all of us have at least dallied with dallying, some have made it a way of life. Hence, the relevant conceptual, theoretical, and empirical work is reviewed, drawing upon correlation, experimental, and qualitative findings. Now and then almost everyone postpones aversive activities. It has increased as post-modern values have permeated much of western society in the last thirty year, Thakkar [2]. Estimates indicate that 80\%$95 \%$ of college students engage in procrastination O'Brien [6] approximately $75 \%$ consider themselves procrastinators and 
almost $50 \%$ procrastinate consistently and problematically Milgram NA [7]. Estimates indicate that $80 \%-95 \%$ of college students engage in procrastination O'Brien [6], approximately $75 \%$ consider themselves procrastinators Pott [8], and almost $50 \%$ procrastinate consistently and problematically.

In academic context, some students deliberately leave course work tasks to the last minute, arguing that the resulting pressure makes them concentrate and gives them the "buzz" they need to produce consistently good work Revelle [9]. If it has the desired effect, then that is good (positive/rational procrastination). However, if deferment or avoidance of required tasks is not producing the desired result, and is leading to negative repercussions for individual and others, then procrastination of action to resolve the situation is unwise (negative/irrational procrastination).

\section{Theoretical Background}

Procrastination and mental health: There are little current empirical and clinical researches on the relationship between procrastination and mental health/well-being especially in childhood and adolescence. Procrastination has a powerful affect on a person's thoughts, feelings, physical health, behavior, and overall functioning Burka [10]. Symptoms often include: craving diversion, ineffective working, last minute rushing, missed deadlines, difficulty in making a start on a piece of work or revision, nagging guilt, disappointment, self-disgust, stress, and depression. There are several different theories as to what causes a person to procrastinate. According to Joseph Ferrari, "Studies show that the procrastination trait comes from the kinds of interactions we have with our parents when we are young."

Most commonly, procrastinators come from households with an authoritarian father, men who are cold and stern. Their children turn to putting off tasks as a form of rebellion. A coping strategy at home does not help them in the outside world. The behavior then becomes part of them and over time, they begin to rationalize things in different ways, Milgram [7], Gehrman, Keinan 1992. Other reasons for procrastinating include poor time management, inability to prioritize, and overload of tasks at a specific time, anxiety about a task, difficulty concentrating, negative self-talk, and avoidance of things that are disliked and/ or difficult Aitkin [11].

Researcher asks why people procrastinate. There are three things that influence the emergence of procrastination; firstly, there are certain personality traits (e.g. high impulsivity) that determine the vulnerability for procrastination. Some people are more seducible to procrastinate than others are. Secondly, self-regulation deficits play an important role. They include little perseverance or deficient time management, but also gaps between one's intention and action. The third issue that contributes to procrastination concerns situational factors such as complexity, plausibility, structuralizing, and attractively of a task, anticipated feedback, experienced autonomy, and social isolation Habelrih and Hicks [12].

The causes of procrastination are complex and as yet far from being fully understood, therefore, it is important to investigate its relationship with mental health levels, and personality traits. However, Steele [13] summarized several studies of the concept in an attempt to identify the cause, and concluded that the following factors impact on individual response to task procrastination: (1) Aversion to the task (Avoidance of unpleasant, boring or difficult tasks for as long as possible), (2) worry about failure (Worry about failing; prefer to be viewed and judged by others as lacking in effort, rather than ability), (3) depression or mood related (low energy/motivation levels, arising depression, or just not in the mood responses to tasks, (4) rebellion (delaying starting tasks because of resentment about the task, or person imposing it); time management issues (under-estimation of time needed to complete set tasks; environmental factors (e.g. place of work and study, have an impact on motivation to start); enjoy working under pressure (relish the "buzz" of working close to the time limits); impulsiveness (easily swayed from one task to anther; pursuit of immediate gratification or sensation- and worry later), Milgram [7]. Researchers suggest that there are five types of procrastinators: Three types of procrastination: (1) The thrill seekers, (2) avoiders, (3) active, (4) decisional and (5) academic procrastinators, Abdallah 2012, in addition, negative/ irrational procrastination, and positive/rational procrastination Gafni and Geri [14], task procrastination and trait procrastination Steel [13].

Whether procrastination can also be considered a personality trait is an empirical question: Does people's level of procrastination show consistency across time and situation. There has been sufficient research to address this issue, and it suggests procrastination has sufficient cross-temporal and situational stability. There appears to be a biological or genetic component to procrastination, Arvey [15]. On the other hand, various studies show a very distinct clustering of related traits: trait procrastination, weak impulse control, lack of persistence, lack of work discipline, lack of time management skill, and the inability to work methodically. It is possibly more fruitful to label this cluster as (lack of) self-control. Despite this overlap, conscientiousness is a broader construct. It has been defined with terms as varied as conformity, socially prescribed impulse control, achievement orientation, cautiousness, morality, organization, thoroughness, and reliability Hogan and Ones [16]. In his research review, Steel [13] investigate the procrastination as personality trait and concluded that the degree that people are self-interested, self-regulatory failure is associated with diminished overall utility, in terms of both mood and performance, Bernstein [3]. Conceptually, procrastination is strongly related to conscientiousness, which itself is consistently linked to better performance, and procrastinators should tend to be worse off in 
terms of both how they feel and what they achieve. Steel studied procrastination and its relationship with following correlates of personality : (1) Task Characteristics, (2) Timing of Rewards and Punishments, (3) Individual Differences, (4) Task Aversiveness, (5) Neuroticism, (6) Extraversion, (7) Irrational beliefs, (8) Low self-efficacy and low self-esteem, (9) Depression, (10) Openness to Experience, (11) Impulsiveness, (12) Conscientiousness, (13) Distractibility, (14) Sensation seeking, (15) Intention-action gap. (16) Organization. He concluded that, strong and consistent predictors of procrastination were task aversiveness, task delay, self-efficiency, and impulsiveness, as well as conscientiousness and its facets of self-control, distractibility, organization, and achievement motivation. These effects prove consistent with temporal motivation theory, an integrative hybrid of expectancy theory and hyperbolic discounting, Steel [13].

In their study, Habelrih and Hicks [12] examines how psychological well-being is related to the concepts of active procrastination and passive (traditional) procrastination. Active and passive procrastination are related insignificantly to each other (we are not dealing with one dimension); but what would be the relationships among psychological well-being, active procrastination and passive procrastination? The different forms of procrastination may have different relationships to well-being and research is scarce; and further, treatment processes for avoiding the negative effects of procrastination should be tailored to the different forms of procrastination. It was hypothesized that psychological Well-Being would be related positively to active procrastination and negatively to passive procrastination. To answer this question, 152 university students aged between 18 and 54, mean age of 23.3 (SD = 18) completed the Active Procrastination Scale, the Passive Procrastination Scale, and Ryff's Scales of Psychological Well-Being. Standard multiple regressions were used, linking psychological well-being, age, gender, active and passive procrastination. The findings show active and passive procrastination are in fact separate constructs and need to be treated differently. Being an active procrastinator can be a sign of healthy Well-Being.

A recent study on the negative health consequences of procrastination suggested that procrastination was associated with higher stress and poor health Tice 1997. The investigation by Sirois [17] sought to clarify and extend these findings by examining the meditational role of stress and health behaviors in the procrastination-illness relationship. It was hypothesized that in addition to stress; a behavioral pathway would be implicated, with poor wiliness behaviors and delay in seeking treatment for health problems mediating the effects of procrastination on health. The model was tested with a sample of university students $(\mathrm{n}=122)$ during a high stress period. As expected, the results indicated that procrastination related to poorer health, treatment delay, perceived stress, and fewer wiliness behaviors. The process analyses supported the meditational role of stress and treatment delay, but not wiliness behaviors, in the
Procrastination-Illness relationship. The model is consistent with current conceptualizations of the personality-health relationship, and presents procrastination as a behavioral style that may increase vulnerability for negative health outcomes.

There are several studies intended to examine the procrastination: with time management Gafni and Geri [14], and with well-being Habelrih and Hicks [12] and its nature and causes Thakkar [2], and among college students ford 2014. But still an important question should be answered, regarding the relationship between procrastination with mental health criteria, gender and developmental stage especially among children and adolescents' that represent the objective of this article. Findings ideated that there is negative correlation between procrastination and university student's mental health Sirois [17]. In another study, it found that much of procrastination's affect on life satisfaction was though anxiety and regard Abdullah 2012. The role of depression or loss of emotional and behavioral control was not taken into account, but to the degree that people are self-interested, self-regulatory failure is associated with diminished overall utility, in terms of both mood and performance. Consequently, procrastinators should tend to be worse off in terms of both how they feel and what they achieve Barrick and Mount [18].

The question of how positive mental health and well-being should be defined remains unresolved. There are several broad and inconsistent definitions being used in current psychological literatures. (Health is the state of efficiency, and Physical, mental, and social well-being, and not just the absence of disease. Although the absence of mental disease have been linked to the psychological health, (negative definition), current researches suggest several attributes and criteria (indexes) that should be measured objectively and subjectively (positive definition), Abd-Alkhaleq [19]. The best definition of mental health is the "Positive emotional, behavioral, and mental state that can be seen in higher level of personal and social adjustment in personality, signed in several attribute aspects" Abdulla 2016. Some researchers indicated that the following attributes have been found to be important for good mental health (1) Positive emotions: overall, how happy do I feel? (2) Engagement: taking an interest in your work and activities (3) Relationships: having people in your life that you care for and who care about you, (4) Meaning and purpose: feeling that what you do in life is valuable and worthwhile, (5) Accomplishment: feeling that what you do gives you a sense of accomplishment and makes you feel competent, (6) Emotional stability: feeling calm and peaceful, (7) Optimism: feeling positive about your life and your future, (8) Resilience: being able to bounce back in the face of adversity, (9) Self-esteem: feeling positive about yourself, (10) Vitality: feeling energetic. In addition, other researchers proposed the following mental health index that include four continuum: (1) Psychological distress vs Psychological well-being, (2) Loss of behavioral-emotional control vs Emotional ties and stability, 
(3) Depression v General positive effect, (4) Anxiety vs life satisfaction. Ryff 1989 stated that there are three interrelated components to psychological well-being: life satisfaction, pleasant affect, and unpleasant affect. Psychological well-being relates to how people subjectively evaluate their lives cognitively and affectively. Thus, for the purposes of the present study, psychological well-being was operational zed as a combination of positive affective states and optimal cognitive and social functioning. This approach is in line with the suggestions of Winefield, Gill, Taylor and Pilkington [20].

\section{Outcome}

The following points can summarize the basic picture that has emerged: (1) The tendency to procrastinate is normal, perhaps even innate; (2) Procrastination is distinguished from prioritization by irrationality. The former occurs when we put off a task on the basis of a plan to do it later that is unrealistic, when later comes around, we put it off again, (3) Beating procrastination is not necessarily about "doing now", it's about taking measures to ensure plan follow-through when do defer a task for a later time, (4) procrastination is more likely with LongTerm deadline, I,e., large windows of time when a task could potentially be done. Stroud [21].

Until recently, the consensus in much research surrounding mental health as a construct that was an opposite of negative states. For example, psychological well-being was seen as "not stressed" or "not depressed", and therefore low scores on Depression- Anxiety, stress or other negative attributes indicated higher psychological mental health and well-being, Libran 2006. With attention to positive aspects, mental health indicates, for instance, happiness or life satisfaction rather than the "opposites of depression and anxiety", according to recent positive psychology movement since the early 2000's though attention to positive aspects of mental health/wellbeing included at least six main variables: sense of autonomy, self-acceptance, purpose in life, positive relations with others, personal growth, and environmental mastery. We therefore used Al-Rahhal's 2010 Scale of Mental Health in our study as not only was a total psychological Well-Being score possible but examination of the contribution of these six positive Well-Being elements could occur, adding considerably to earlier literature that emphasized "not being depressed anxious or stressed" as mental health. (6) There are interference or overlap between personality traits and aspects or index of mental health and wellbeing. However, little attention has been spending to investigate the relationship between procrastination and aspects/signs of positive mental health among children and adolescents, which represent the objective of this study. It contributes to the research literature and investigates the procrastination and its relationship to mental health of children and adolescents, on one hand, and highlight if there are significant differences regarding tow variables: gender and developmental stage.

\section{Purpose of the Study: The aim of the study is to assess:}

a. The differences between boys and girls in procrastination.

b. The differences between children and adolescents in procrastination.

c. The connection between procrastination and positive mental health indexes.

\section{Questions of the Study: The study addresses the following specific questions:}

a. Are there significant differences in procrastination between boys and girls?

b. Are there significant differences in procrastination between children and adolescent?

c. What is the relationship (correlation) between procrastination and mental health of the children and adolescents enrolled in schools?

\section{Methodology}

\section{Participants}

The sample of participants size was (268) students (133) males and (135) females, ranging between 10-15 years old, selected randomly from basic teaching schools in Aleppo city for the 4 th , 5th grades of children and 7th, 8th, 9th grades of adolescents, and gender (males and females).

\section{Materials}

The measures of the stud were: Procrastination Scale (PS) is a 44 items self-report scale which constructed by the researcher depending on psychological literatures and previous scales such as Ferari [21] Procrastination Test Ferrari [21] and Tuckman procrastination Scale Tuckman 1991. A higher score indicates a higher level of active procrastination. The present study found very good internal consistency for the current sample, (Cronbach's Alpha $=0.88$ ), and good stability with test-retest reliability of 0.86 .

Mental Health Scale (MHS) constructed by Al-Rahhal 2011 to measure the mental health of children and adolescents. This scale designed, depending on existential and phenomenological theory in psychotherapy. It consisted 60-items for assessing criteria / indexes of mental health that include : (item's number $1,11,21,41,51$ ) for measuring self and other awareness and acceptance , (item's number 2, 12, 22, 32, 42, 52), for trust of one's self and others, (items: 3, 13, 23, 43, 53) for assessing wiliness freedom, and responsibility, (items: 4, 14. 24, 34. 54 ) for scaling personal adjustment, (items: $5,15,25,35,45,55$ ) for social adjustment, $(6,16,26,36,46,56$, for courage and problem solving, (items: 7, 17, 27, 37, 47, 57, ) for assessing straightness., (items: $8,18,28,38,48,58$ ) for assessing reality and object's 
perception, (items: 9, 19, 29, 39, 49, 59,) for love of one's self and others, and finally, (items: 10, 20, 30, 40, 50, 60) for life's purpose and meaning. The Items scored on a 5-point LikertType Scale ranging from 1 for false of me to 5 for true of me. The present study found good internal consistency for the current sample, (Cronbach's Alpha $=0.81$ ), and good stability with TestRetest reliability of 0.84 .

\section{Data Collection and Analysis}

Descriptive statistics have been used (M, SD) correlation coefficient for measuring the relationship between procrastination and mental health index/aspects, and T-test for accounting the differences in procrastination regarding gender and developmental stage's variables.

\section{Results}

Prior to analysis, Scores on the items of the scales were analyzed to answer the question of the study.

Question One: "Are there significant differences in procrastination between boys and girls?" The first question was to describe, statistically, the procrastination according to the variable of gender. The results of the analyzed data presented in Table 1.

Table 1: The results in this are revealed that significant differences exist between boys and girls.

\begin{tabular}{|c|c|c|c|c|c|c|}
\hline \multirow{2}{*}{ Variables } & \multicolumn{2}{|c|}{ Boys } & \multicolumn{2}{c|}{ Girls } & \multirow{2}{*}{ T. value } & \multirow{2}{*}{ Sig. } \\
\cline { 2 - 5 } & $\mathbf{M}$ & $\mathbf{S}$ & $\mathbf{2}$ & $\mathbf{2}$ & \multirow{2}{*}{0.43} \\
\hline Procrastination & 39.18 & 14.45 & 37.22 & 13.34 & & 0.05 \\
\hline
\end{tabular}

The results indicated that males differ significantly from females regarding procrastination (T. Value $=2.43$, Sig. 0.05 ) Males more procrastinating than females.

The results in Table 1 revealed that significant differences differ significantly from females regarding procrastination (T. exist between boys and girls. The results indicated that males Value $=2.43$, Sig. 0.05) Males more procrastinating than females.

Table 2: The results in this are revealed that significant differences exist between children and adolescents.

\begin{tabular}{|c|c|c|c|c|c|c|}
\hline \multirow{2}{*}{ Variables } & \multicolumn{2}{|c|}{ Children } & \multicolumn{2}{|c|}{ Adolescents } & T. value & Sig. \\
\hline & M & S & $\mathbf{M}$ & $\mathbf{S}$ & & \\
\hline Procrastination & 41.23 & 14.51 & 43.98 & 13.25 & 2.07 & 0.05 \\
\hline
\end{tabular}

The results indicated that Adolescents tending to procrastinate more than children, and the difference was significantly $(\mathrm{T}$. Value $=2.67$, Sig 0.05 ) Males more procrastinating than females.

Question Two: "Are there significant differences in procrastination between children and adolescents?". Second question was to describe, statistically, the procrastination according to the variable of developmental stage (childhood, adolescence). The results of the analyzed data presented in Table 2 .

The results in Table 2 revealed that significant differences exist between children and adolescents. The results indicated that Adolescents tend to procrastinate more than children, and the difference was significantly (T. Value $=2.67$, Sig. 0.05) Males more procrastinating than females.

Question Three: "What is the correlation between procrastination and mental health of the children and adolescents enrolled in schools?" This question was to assess the relationship between procrastination and mental health. The results of the statistically analyzed data are presented in Table 3.

Table 3: The results in this showed that there are significantly positive correlations between procrastination and the following indexes of mental health: Awareness and acceptance of one's self and others $(r=0.24)$, personal and social adjustment $(r=0.25,0.13)$, courage and problemsolving ( $r=0.26)$ life's purpose and meaning $r=0.22)$ but significantly negative correlation was founded between procrastination and other aspects of mental health (Trust in one's self and other $r=0.66$; Wiliness freedom, and responsibility $r=0=54$, straightness $r=0.36$, perception of reality and objects; and finally $r=0.45$, Love of one's self and others $r=0.31$ ).

\begin{tabular}{|c|c|c|}
\hline Variables & Procrastination R \\
\hline Awareness and acceptance of one's self and others & $0.24^{*}$ \\
\hline Trust in one's self and other & $-0.66^{*}$ \\
\hline Wiliness freedom, and responsibility & $-0.544^{*}$ \\
\hline Personal adjustment & $0.25^{*}$ \\
\hline Social adjustment & 0.13 \\
\hline Courage and problem-solving & $0.26^{*}$ \\
\hline Straightness. & $-036^{*}$ \\
\hline
\end{tabular}


Psychology and Behavioral Science International Journal

\begin{tabular}{|c|c|}
\hline Perception of reality and objects & $-0.45^{*}$ \\
\hline Love of one's self and others & $-0.31^{*}$ \\
\hline Life's purpose and meaning & $0.22 *$ \\
\hline * Sig. 0.01 & \\
\hline
\end{tabular}

The results in Table 3 showed that there are significantly positive correlations between procrastination and the following indexes of mental health: Awareness and acceptance of one's self and others $(r=0.24)$, personal and social adjustment $(r=0.25$, $0.13)$, courage and problem-solving $(r=0.26)$ life's purpose and meaning $r=0.22$ ) but significantly negative correlation founded between procrastination and other aspects of mental health (Trust in one's self and other $r=0.66$; Wiliness freedom, and responsibility $r=0=54$, straightness $r=0.36$, perception of reality and objects; and finally $r=0.45$, Love of one's self and others $\mathrm{r}=0.31$ ).

\section{Discussion}

The aim of this study was to examine the relationship of procrastination and variables of gender and developmental stage on the one hand, and mental health on the other hand.

Regarding the first question, the finding showed differences between boys and girls in procrastination. This finding showed that tending to procrastinate more than girls did. The anticipated influence of gender on procrastination is difficult to predict. Previous investigation into gender differences and the related construct of self-control has found mixed results Feingold [22]. Men may score higher, lower, or the same as women depending on the measure. However, meta-analytic results do show that girls score higher on effortful control than boys Else Quest [23]. On balance then, one could expect procrastination to be weakly associated with males, Ferrari [21].

Regarding the second question, finding showed significant differences between children and adolescents in procrastination. The finding indicated that adolescents score higher than children do in procrastination. This result opposed to the previous researches that demonstrated, People should procrastinate less as they age and learn. As O'Donoghue and Rabin [24] concluded, "Many people who procrastinate only moderately do so not because of intrinsic self-control, but because they have developed schemes to overcome procrastination". It is evident that people can learn to avoid procrastination but this is depending on the personality traits and experiences in general on one hand and on the demands of developmental stage on the other hand.

The third result demonstrated that there is significantly positive correlation between procrastination and some aspects or indexes of mental health (Awareness and acceptance of one's self and others, personal and social adjustment, life's purpose and meaning), but significantly negative correlation found between procrastination and other aspects of mental health: Trust in one's self and other; Wiliness freedom, and responsibility, straightness, perception of reality and objects, and finally, Love of one's self and others. This finding support the previous finding that showed When psychological WellBeing was divided into its component facets and these were entered as independent predictor variables (against the active procrastination criterion) Habelrih and Hicks [12]. On the other hand, the significant positive mental healths facets may predictive of active procrastination were negative mental health facets may predictive of passive procrastination. The purpose in life is an important construct in Logo-Therapy and humanistic positive psychology theory, and regarding this facet, Habelrith and Hicks [12] indicated that it is unclear why a sense of purpose in life would be negatively related to active procrastination.

However, it is perhaps plausible that if we have a low sense of purpose we may not be "active" in our decisions about procrastination; and, perhaps more strongly, if we do have a strong sense of purpose then procrastinating at all would get in the way of what one is seeking to achieve and what is highly valued for the individuals. But these are speculation and need to be examined in further research. These are interesting findings raising that procrastination negatively related to Trust in one's self and other, Wiliness freedom, and responsibility, straightness; perception of reality and objects; and finally, Love of one's self and others. And this finding can be explained in referring to Psychological-Social Needs, developmental tasks or demands, and to the cognitive development in childhood and adolescence to But these remain speculation and need to be examined in further research focus on the types of procrastination (active, avoidant, academic...) and its relationship to personality traits and mental health criteria. When assessing a psychological construct as complex as procrastination, the parts must be identified clearly and examined from multiple perspectives. This raises concerns for those who may prefer the construct and measurement methods. However, procrastination is indeed complex, and further research into the construct and its multiple facets is needed.

\section{Conclusion}

This study examined procrastination and its relationship with criteria of mental health of children and adolescents, and the impact of gender and developmental stage on it. The finding revealed that boys tending to procrastinate more than female, and adolescent more than children. Another finding indicated 
that there are significantly positive correlation between procrastination and some aspects/indexes of mental health (Awareness and acceptance of one's self and others, personal and social adjustment, life's purpose and meaning), but significantly negative correlation founded between procrastination and other aspects of mental health: Trust in one's self and other; Wiliness freedom, and responsibility, straightness, perception of reality and objects; and finally, Love of one's self and others. We conclude that by demonstrating that mental health criteria has different predictive effects on procrastination, relating to its type, and the current research project supported the need for separation of procrastination into few distinct concepts.

These findings lead to significant recommendations: Investigation of the relationship between procrastination and demands of developmental stages in childhood and adolescence, Examine the correlation between aspects of positive mental health and forms of procrastination (a) The thrill seekers, (b) Avoiders,(c) active, (d) Decisional and (e) Academic procrastinators (3) Another issue that should be further studied within informing science research is the need to use other methodology such developmental longitudinal research method, experimental method to highlight the "cause-result" hypothesis in the relation of psychological health-procrastination [25-32].

\section{Acknowledgment}

The author is thankful to his Colloquies of the department of Counseling Psychology at Aleppo University for reviewing the instrument of the research, and to psychological counselors in the schools for supervision and their assistance in application of the research scales.

\section{References}

1. Brown RT (1991) Helping students confront and deal with stress and Procrastination. Journal of College Student Psychotherapy 6(2): 87102.

2. Thakkar N (2010) Why procrastinate: An investigation of the the root causes behind procrastination. Lethbridge Undergraduate Research.

3. Bernstein P (1998) against the gods: The remarkable story of risk. Wiley, New York, USA.

4. Chu AHC, Choi JN (2005) Rethinking procrastination: Positive Effects of "active" procrastination behavior on attitudes and performance. J Soc Psychol 145(3): 245-264.

5. Ferrari J R (1992) Psychometric validation of two procrastination inventories for adults: Arousal and avoidance measures. Journal of Psychopathology and Behavioral Assessment 14(2): 97-110.

6. O'Brien WK (2002) Applying the Trans theoretical model to academic procrastination. Unpublished doctoral dissertation, University of Houston, Texas, USA.

7. Milgram NA (1991) Procrastination. In R Dulbecco (Edn.), Encyclopedia of human biology Academic Press, New York, USA.

8. Potts TJ (1987) Predicting procrastination on academic tasks with Self-report personality measures. Dissertation Abstracts International, Hofstra University, New York, USA.
9. Revelle W (1997) Extraversion and impulsivity: The lost dimension? In: H Nyborg (Edn.), the scientific study of human nature: Tribute to HansJ Eysenck at eighty, Pergamon/Elsevier Science: pp. 189-212.

10. Burka JB, Yuen LM (1983) Procrastination: Why you do it, what to do about it. Reading, Addison-Wesley, Massachusetts, USA.

11. Aitken ME (1982) A personality profile of the college student procrastinator (Doctoral dissertation, University of Pittsburgh, 1982). Dissertation Abstracts International 43: 722.

12. Habelrih EA, Hicks RE (2015) Psychological well-being and its relationship with active and passive procrastination. International Journal of psychological studies 7(3): 25-34.

13. Steel P (2007) The nature of procrastination: A meta- analytic and theoretical review of quintessential self-regulatory failure. Psychological Bulletin 133 (1): 65-94.

14. Gafni R, Geri N (2010) Time management: Procrastination tendency in individual and collaborative tasks. Interdisciplinary Journal of information, Knowledge, and management 5: 115-125.

15. Arvey RD, Rotundo M, Johnson W, Mc Gue M (2003) The Determinants of leadership: The role of genetics and personality. Paper Presented at the $18^{\text {th }}$ Annual Conference of the Society for Industrial and Organizational Psychology, Florida, USA.

16. Hogan J, Ones DS (1997) Conscientiousness and integrity at work. In $R$ Hogan, J Johnson, S. Briggs (Eds.), Handbook of personality Psychology (pp. 849-870). New York: Academic Press.

17. Sirois FM, Melia-Gordon, Timothy ML, Pychyl A (2002) 'I'll look after my health, later": an investigation of procrastination and health. Personality and Individual Differences 35: 1167-1184.

18. Abd Al-Khaleq A (2001) Origin of mental health. Al- Eskandareya: Dar Al-Marifa.

19. Winefield HR, Gill TK, Taylor AW, Pilkington RM (2012) Psychological well-being and psychological distress: Is it necessary to measure both? Theory, Research and Practice 2: 1-14.

20. Stroud S (2010) Is procrastination weakness of will? In the thief of time, edited by Chrisoula Andreou and mark D, Oxford University press, UK.

21. Frrari J, Olivette M (1994) Parental authority and the development of female dysfunctional procrastination. Journal of research in personality 28: 87-100.

22. Feingold A (1994) Gender differences in personality: A meta-analysis. Psychol Bull 116(3): 429-526.

23. Else-Quest N, Hyde J, Goldsmith H, Van Hulle C (2006) Gender differences in temperament: A meta-analysis. Psychol Bull 132(1): 3372.

24. 0 Donoghue T, rabin M (1999) Incentives for procrastinators. Quarterly Journal of economics 114(3): 769-816.

25. Barrick MR, Mount MK (2003) Impact of meta-analysis methods on understanding personality-performance relations. In KR Murphy (Edn.), Validity generalization: A critical review pp. 197-221.

26. Foed J (2014) Procrastination and the college student: An analysis on contributing factors and academic consequences. Education and psychology.

27. Loewenstein G, Elster J (1992) Choice over time. New York: Russell Sage Foundation.

28. Milgram NA, Sroloff B, Rosenbaum M (1988) The procrastination of everyday life. Journal of Research in Personality 22: 197-212. 
29. Silver M, Sabini J (1981) Procrastinating. Journal for the Theory of Social Behavior 11(2): 207-221.

30. Simon HA (1994) The bottleneck of attention: connecting thought with motivation. Nebr Symp Motiv 41: 1-21.

This work is licensed under Creative Commons Attribution 4.0 License

DOI: $10.19080 /$ PBSIJ.2017.04.555649
31. Sirois FM, Tosti N (2012) Lost in the moment? An investigation of procrastination, mindfulness and well-being. Cognitive Behavior Therapy 30(4): 237-248.

32. Van Eerde W (2003) Procrastination at work and time management training. Journal of psychology 137: 421-434.

\section{Your next submission with JuniperPublishers will reach you the below assets}

- Quality Editorial service

- Swift Peer Review

- Reprints availability

- E-prints Service

- Manuscript Podcast for convenient understanding

- Global attainment for your research

- Manuscript accessibility in different formats (Pdf, E-pub, Full Text, Audio)

- Unceasing customer service

Track the below URL for one-step submission https://juniperpublishers.com/online-submission.php 